\title{
Integrating policy, system strengthening, research and harmonized services delivery for scaling up drinking water safety in Bangladesh
}

\author{
B. Onabolu ${ }^{1}$, E. Khan ${ }^{2}$, J. Chowdhury ${ }^{2}$, N. Akter ${ }^{1}$, S.K. Ghosh ${ }^{2}$, M.S. Rahman ${ }^{2}$, P. Bhattacharya ${ }^{3}$,

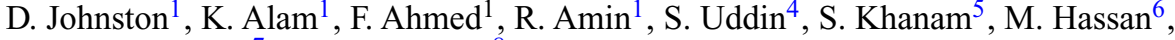 \\ M. von Brömssen ${ }^{7}$ \& K.M. Ahmed ${ }^{8}$ \\ ${ }^{1}$ UNICEF Bangladesh, Dhaka, Bangladesh \\ ${ }^{2}$ Department of Public Health Engineering, Dhaka, Bangladesh \\ ${ }^{3}$ KTH-International Groundwater Arsenic Research Group, Department of Sustainable Development, \\ Environmental Science and Engineering, KTH Royal Institute of Technology, Stockholm, Sweden \\ ${ }^{4}$ Asia Arsenic Network, Dhaka, Bangladesh \\ ${ }^{5}$ Environment and Population Research Center, Dhaka, Bangladesh \\ ${ }^{6}$ Village Education and Resource Center, Dhaka, Bangladesh \\ ${ }^{7}$ Ramböll Sweden AB, Stockholm, Sweden \\ ${ }^{8}$ Department of Geology, University of Dhaka, Dhaka, Bangladesh
}

\begin{abstract}
The WASH Sector Development Plan (2011-2025) recognizes the absence of harmonized approaches as the root challenge to scaling up drinking water safety in Bangladesh. UNICEF is supporting the Government of Bangladesh (GoB) through the Department of Public Health Engineering (DPHE) and Policy Support Branch to re-engineer its approach to drinking water safety by integrating policy, systems strengthening \& sustainable services delivery at national and sub-national levels. Some of the key contributions to the sector include the implementation of the UNICEF-DPHE Arsenic Safe Union model with the declaration of 106 Arsenic Safe Villages, reduction in arsenic contamination rates of new tubewells, a system for preventing elite capture of water points, and the adoption of the ASU model in a \$240 million arsenic mitigation drinking water project using domestic resources. Relatedly, a Policy Support Branch has been established, the sector coordination mechanisms revised, WASH bottleneck analysis is ongoing \& the National Implementation Plan on Arsenic has been reviewed: Next steps include the professionalisation of drilling by local drillers through a partnership with KTH, Sweden, the GoB and UNICEF.
\end{abstract}

\section{INTRODUCTION}

Bangladesh has made laudable progress towards achieving its goal of ensuring access to safe drinking water for all its citizens and achieved the Millennium Development Target for drinking water (GED, 2016). However in the context of the SDG 6.1 there is a gap between coverage and safety of the improved water sources. Although $97.8 \%$ of the population have access to improved water sources nationally, about $65 \%$ of the population lack access to drinking water that is arsenic safe and free from microbial contamination and 19.7 million people are exposed to arsenic from improved water sources that exceed the BDWS $(50 \mu \mathrm{g} / \mathrm{L})$ (BBS and UNICEF, 2015).

The Sector Development Plan (2011-2025) identifies the challenges to scaling up drinking water safety in Bangladesh as geogenic arsenic, iron, manganese \& salinity; environmental vulnerability; inadequate prioritization of arsenic prone areas; private sector capacity; and absence of harmonized sector wide approaches. This paper focuses on the sustainable services delivery component.

\section{PROCESS}

\subsection{Sustainable services delivery-scalable DPHE-UNICEF Arsenic Safe Union Model}

The Arsenic Safe Union (ASU) model uses the village as the unit of intervention and not the individual water source. It emphasizes vulnerability risk assessment for selecting most arsenic prone areas, local government ownership, provision of sanitation and safe water supply, pro-poor selection criteria, geocoded water point installations, real time reporting and information management, evidence based decision making and advocacy. The final step is the declaration, verification, and certification of the union as arsenic safe.

The ASU Model is built on the UNICEF-DPHE arsenic mitigation protocol (Fig. 1) and arsenic safe 


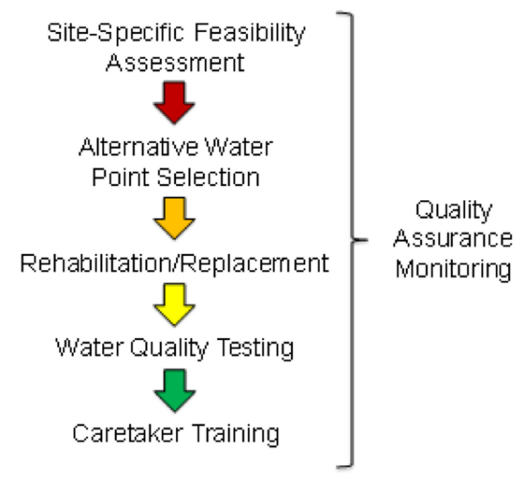

Figure 1. Arsenic Mitigation Protocol.

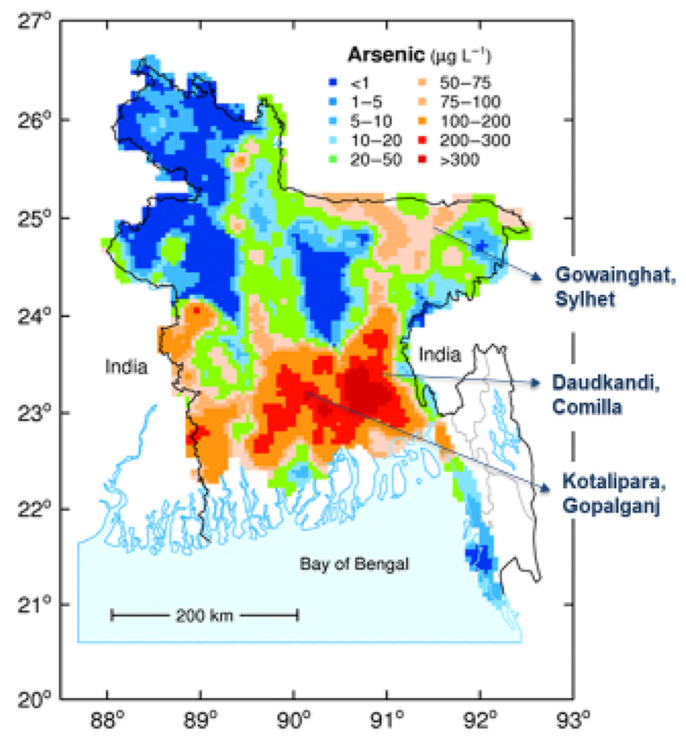

Figure 2. Arsenic prone intervention areas.

village concept with the inclusion of vulnerability risk assessments to select most vulnerable administrative units for intervention.

\subsection{Scalable DPHE-UNICEF Arsenic Safe Union model}

UNICEF in collaboration with DPHE designed the ASU concept in 2015. The concept was implemented between January 2016 and December 2017 in a total of 15 unions in three Sub-districts of three districts in Bangladesh (Fig. 2) with funding from Swedish International Development Agency and UNICEF.

The project was implemented in partnership with Asia Arsenic Network, Environment and Population Research Center and Village Education and Research Center. The Project aimed to reach 100,000 people with safe drinking water and 300,000 people with safe sanitation and increased awareness about arsenic and hygiene.

\subsection{Integration with policy, planning, systems strengthening and resource mobilization}

In addition to advocating for a common approach to services delivery, UNICEF Bangladesh engaged with government, development partners and the sector to improve coordination, domestic and foreign resource mobilization for scaling up drinking water safety, improved information management and mechanisms to close the gap between policies and implementation of the policies.

\subsection{Adoption of vulnerability risk assessment by national and sub-national government for selection of most vulnerable areas}

Secondary data was used to select the As prone districts and sub-districts (Upazilas) (BBS \& UNICEF, 2015; Flanagan et al., 2012). Then vulnerability risk assessments were used to select 15 most As contaminated unions in the intervention upazilas. The vulnerability indices were percentage of As contamination, number of arsenicosis patients, safe water supply to population ratio. The acceptance of this by government is a significant achievement and change from the past when allocation was not based on need or degree of contamination.

\section{RESULTS: KEY CONTRIBUTIONS TO THE SECTOR}

\subsection{Blanket arsenic screening}

All drinking water sources $(n=21,540)$ in the intervention sites were screened for As and tubewell depth Some of the findings of the screening results are presented in Table 1.

The survey indicated that nearly $88 \%$ of the wells were shallow ( $<500 \mathrm{ft})$ and the remaining $12 \%$ were deep wells, and nearly $97 \%$ of the wells were functional. Combining both the shallow and the deep wells about $54 \%$ were found to be safe in terms of the Bangladesh drinking water standard $\left(50 \mu \mathrm{g} \mathrm{L}^{-1}\right)$.

Arsenic contamination was mostly prevalent in the shallow tube-wells (52\%) and mostly confined to those provide privately.

\subsection{Quality assurance (QA) monitoring}

About $80 \%$ of samples were declared either safe or unsafe $\left(0.05 \mathrm{mg} \mathrm{L}^{-1}\right)$ by both field kit (Econo-quick) and laboratory (Atomic Absorption Spectrophotometer) while some false positives $(9 \%)$ and false negatives $(11 \%)$ indicated discrepancy between the two methods.

\subsection{Baseline survey alignment of indicators with SDG 6.1}

A water and sanitation KAP baseline survey was conducted in 750 households using SDG 6.1 and 6.2 indicators. The findings indicated a significant decrease from coverage figures when safety and access on premises was considered (Fig. 3). 
Table 1. Summary of the results of the screening of the drinking water sources.

\begin{tabular}{|c|c|c|}
\hline \# & Criteria & Percentage \\
\hline 1. & Functional status & $97 \%$ \\
\hline 2. & $\begin{array}{l}\text { Depth of the wells } \\
>500 \mathrm{ft} \\
<500 \mathrm{ft}\end{array}$ & $\begin{array}{l}12 \% \\
88 \%\end{array}$ \\
\hline 3. & $\begin{array}{l}\text { Arsenic contamination status } \\
\text { Shallow and deep wells (combined) } \\
\text { Safe } \\
\text { Unsafe } \\
\text { Arsenic contamination in deep } \\
\text { tube-wells } \\
\text { Arsenic contamination in } \\
\text { shallow tube-wells }\end{array}$ & $\begin{array}{l}54 \% \\
46 \% \\
1 \%\end{array}$ \\
\hline 4. & $\begin{array}{l}\text { Provider (Shallow and deep wells, } \\
\text { combined) } \\
\text { Private } \\
\text { Government } \\
\text { NGO }\end{array}$ & $\begin{array}{l}83 \% \\
12 \% \\
5 \%\end{array}$ \\
\hline 5. & $\begin{array}{l}\text { Provider of shallow wells } \\
\text { Private } \\
\text { Government } \\
N G O\end{array}$ & $\begin{array}{l}83 \% \\
5 \% \\
12 \%\end{array}$ \\
\hline 6. & $\begin{array}{l}\text { Arsenic contamination of } \mathrm{TW} \text { by provider } \\
\text { Private } \\
\mathrm{NGO}\end{array}$ & $\begin{array}{l}59 \% \\
41 \%\end{array}$ \\
\hline
\end{tabular}

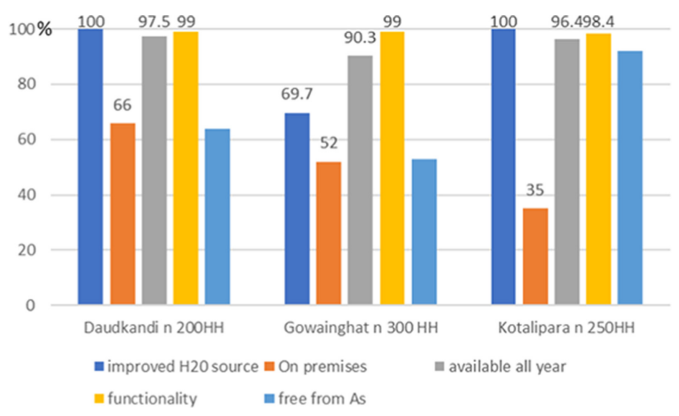

Figure 3. SDG 6.1 - Baseline survey results

\subsection{The use of GIS mapping for evidence based advocacy and decision making}

The data from site-specific feasibility assessment (before intervention) and new water points was converted into GIS maps and used for advocacy to government to prioritize vulnerable villages and change from the practice of equal allocations and as evidence of the successful interventions.

\subsection{Three tier monitoring - reduction in proportion of arsenic contaminated wells}

The proportion of new wells that were As contaminated $\left(0.05 \mathrm{mg} \mathrm{L}^{-1}\right)$ reduced from $9 \%$ to $3 \%$ and $\mathrm{As}, \mathrm{Fe}$,
Mn and salinity levels were determined for mitigation before handing over to users.

\subsection{Three tier monitoring - reduction in elite capture of project tubewells}

Site selection criteria integrated with GPS coordinates of agreed and actual sites were monitored to ensure water sources were allocated to the poor as planned.

\subsection{Scaling up-adoption of Arsenic Safe Union model by Government of Bangladesh}

DPHE has adopted the ASU model for use in a \$240 million arsenic mitigation project in 29 arsenic prone districts.

\section{CONCLUSION AND NEXT STEPS}

The Arsenic Safe Union model if integrated with policy and systems strengthening interventions is scalable for sector wide As mitigation. UNICEF is working with KTH Royal Institute of Technology in Sweden to integrate science with indigenous knowledge using the Sediment Colour Tool to improve private sector effectiveness in safe water drilling. UNICEF is supporting the development of low cost As test kit locally, arsenic safe union operational guidelines, integration of arsenicosis in the health information system and the Implementation of national plan for arsenic mitigation by all stakeholders.

\section{ACKNOWLEDGEMENTS}

The financial contribution of the Swedish International Development Agency (Sida Contribution 52170040) is appreciated.

\section{REFERENCES}

Bangladesh Bureau of Statistics (BBS) and UNICEF Bangladesh, 2015. Bangladesh Multiple Indicator Cluster Survey 2012-2013, Progotir Pathey: Final Report. Dhaka, Bangladesh: Bangladesh Bureau of Statistics (BBS) and UNICEF Bangladesh.

General Economics Division (GED), 2016. Millennium Development Goals (MDGS): End-Period Stocktaking and Final Evaluation (2000-2015). Dhaka, Bangladesh: General Economics Division (GED), Bangladesh Planning Commission, Government of the People's Republic of Bangladesh.

Flanagan, S.V., Johnston, R.B., \& Zheng, Y., 2012. Arsenic in tube well water in Bangladesh: health and economic impacts and implications for arsenic mitigation. Bulletin of the World Health Organization, Volume 90, Number 11, November 2012, 839-846. Available at: https://www.who.int/bulletin/volumes/90/11/11101253/en/ [Last accessed: 31 May 2018] 